\title{
Case Study: Information Processing Speed and Accuracy in Basketball Players With and Without Functional Ankle Instability
}

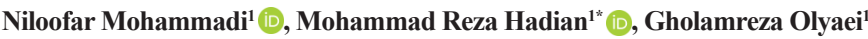

1. Department of Physiotherapy, School of Rehabilitation, Tehran University of Medical Sciences, Tehran, Iran.

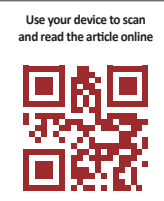

Citation: Mohammadi N, Hadian MR, Olyaei Gh. Information Processing Speed and Accuracy in Basketball Players With and Without Functional Ankle Instability. Journal of Modern Rehabilitation. 2019; 13(3):179-184. http://dx.doi.org/10.32598/ JMR.13.3.179

http://dx.doi.org/10.32598/JMR.13.3.179

Article info:

Received: 06 Dec 2018

Accepted: 27 Apr 2019

Available Online: $01 \mathrm{Jul} 2019$

\section{Keywords:}

Neurocognitive function, Reaction time task, Functional ankle instability

\begin{abstract}
Introduction: Ankle sprain is a common sports injury that can cause Functional Ankle Instability (FAI). Neurocognitive function impairment had been reported in subjects with musculoskeletal injuries. Consequently, information processing deficits might be associated with FAI. This study aimed to compare information processing speed and accuracy in athletes with and without FAI.
\end{abstract}

Materials and Methods: Eighteen control healthy male basketball players and 18 male basketball players with FAI voluntarily participated in the study. They were matched according to age, height, weight, duration of physical activity, and upper-limb dominance. The neurocognitive function of subjects was assessed with the computerized neurocognitive test. The computerized neurocognitive assessment is based on the presentation of ' $\mathrm{X}$ ' on a computer monitor and includes detection (i.e. simple reaction time [SRT]) or identification (i.e. Choice Reaction Time [CRT]).

Results: Significant differences were observed between study groups in the SRT, CRT, and the number of errors $(\mathrm{P}<0.001)$. Subjects in the control group had a shorter reaction time and fewer errors.

Discussion: Athletes with FAI had significantly slower reaction times. FAI affects processing speed and accuracy, which may be modifiable through the performance of exercises designed to accelerate neurocognitive processing of visual input.

\section{Introduction}

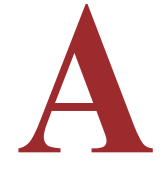

pplication of neuropsychological tests as an assessment tool in sports concussion had rapidly grown in the United States since its introduction to the sports medicine community by Barth et al. in the 1980s [1]. During the past two decades, computerized neurocognitive tests have become increasingly popular due to their several benefits. These benefits include standardization of stimulus presentation, shorter administration time, rapid and accurate analysis and storage of data, easy comparison with prior test performance, and the existence of multiple equivalent forms of the test to

* Corresponding Author:

Mohammad Reza Hadian, PhD.

Address: Department of Physiotherapy, School of Rehabilitation, Tehran University of Medical Sciences, Tehran, Iran.

Tel: +98 (910) 9294639

E-mail: hadianrs@sina.tums.ac.ir 
minimize the practice effects such as learning $[1,2]$. The computerized neurocognitive tests can accurately measure the reaction time as short as one millisecond. This accuracy gives computerized testing a considerable advantage over more traditional test methods in detecting the subtle impairments in central processing speed [3].

Prolonged neurocognitive reaction time is now widely recognized as an essential indicator of impaired brain function following a concussion [4-12], which could be quantified by computerized testing procedures that had been shown to provide highly reliable measurements [13]. Swanik et al. [14] reported the first evidence of a possible link between brain function quantified by a computerized neurocognitive test and knee injury risk. Neurocognitive reaction time appeared to be an indicator of elevated risk for lower extremity sprains and strains [15].

Besides, slow reaction time was reported in individuals with musculoskeletal injuries [16-19]. Functional ankle instability (FAI) is a condition that occurs in approximately $40 \%$ of patients with an ankle sprain [20]. It is defined as the "disabling loss of reliable static and dynamic support of a joint" and a "tendency for the foot to give way" [21, 22]. Despite successful management of pain, range of motion, muscle strength and balance, a recurrent ankle sprain is a common problem, and other factors such as neurocognitive factors have overlooked in this regard.

The amount of time required for visual perception of a stimulus, information processing, and response to the stimulus may be associated with the athletes' situational awareness and their capability for the rapid generation of an appropriate motor response to external forces [15].

Neurocognitive parameters, such as reaction time, processing speed, visual memory, and verbal memory, were well established in the neuropsychology literature as indirect measures of cerebral performance. Situational awareness, arousal, and attentional resources of the individual might influence these areas of neurocognitive function and affect the complex integration of vestibular, visual, and somatosensory information needed for neuromuscular control [4, 11, 23].

Previous studies had not attempted to compare information processing speed and accuracy in athletes with and without FAI. Therefore, we aimed to evaluate the information processing speed and accuracy in athletes with and without FAI.

\section{Materials and Methods}

\section{Study Subjects}

A total of 18 male basketball players with FAI and 18 healthy control male basketball players were selected by non-probability convenient sampling method from basketball teams attending Karaj City professional leagues. Our study was a case-control one. Athletes were matched according to their age, height, weight, duration of physical activity, and upper-limb dominance. The subjects in FAI and control group had a Mean \pm SD age, weight, and height of $23.33 \pm 2.35,22.89 \pm 2.59$ years, $68.17 \pm 13.22$, $67.28 \pm 12.54 \mathrm{~kg}$ and $1.78 \pm 0.10,1.79 \pm 0.13 \mathrm{~m}$, respectively. All subjects were college basketball players and signed an informed consent form approved by the Ethics Committee of the Tehran University of Medical Sciences.

Subjects with FAI were included in the study if their ages were between 20 and 30 years, had at least 1 significant unilateral inversion sprain of either ankle that resulted in pain, swelling, and loss of function within last year, followed by more than 1 repeated injury or the perception of ankle instability or "giving way", no recent lower-limb or low back pathology, no evidence of mechanical instability as assessed by the anterior drawer and talar tilt tests, no reported history of ankle injury within the last 3 months. Subjects in the FAI group had 1 to 3 ankle sprains within the previous 12 months, and the Cumberland Ankle Instability Tool (CAIT) score lower than 24 [24-27].

Subjects were included in the control group if their ages were between 20 and 30 years and had no history of ankle sprains [20]. The information was gathered by a trained physical therapist using a self-report questionnaire and clinical examination. Subjects would be excluded from the control group if they reported a history of ankle sprain or perception of giving-way in the ankle. Subjects would be excluded from both groups if they were using any medicine that could affect their cognitive function or reluctant to continue the test [24].

\section{Questionnaire}

All subjects completed a questionnaire providing baseline characteristics, including age, and duration of physical activity and subjects with FAI were asked to complete CAIT, too. 


\section{Procedure}

Neurocognitive Test. The subjects were allowed one practice trial to familiarize themselves with the cognitive test. All athletes completed a computerized neurocognitive test, Deary-Liewald Reaction time Task (DLRT). Each athlete wore headphones during the test to minimize outside distractions. The computerized neurocognitive assessment was based on the presentation of ' $\mathrm{X}$ ' on a computer monitor and included detection (i.e. Simple Reaction Time [SRT]) or identification (i.e. Choice Reaction Time [CRT]). In SRT measurement, ' $\mathrm{X}$ ' mark appears in the relevant box on the screen and each time it has appeared, the athlete must press the space key as quickly as possible.

At least 20 trials were completed and reaction time was recorded. In CRT measurement, there were four boxes on the screen. ' $\mathrm{X}$ ' mark appears in one of them and the athlete must press the correct key for that box as quickly as possible. At least 40 trials were completed and reaction time and error were recorded. Tests order was random. The subject took a 30-s rest between trials, and at least 1 minute of rest between tests. Each subject performed each test three times, and the mean of his scores was recorded as the final score.

\section{Statistical analysis}

All data were imported into SPSS V. 16. Normal distribution was evaluated using the Kolmogorov-Smirnov test. The between-group comparison was made using the independent samples t test to compare performance differences between FAI and control group for the neurocognitive tests.

\section{Results}

There was no statistically significant difference in terms of age $(\mathrm{P}=0.442)$, weight $(\mathrm{P}=0.767)$, height $(\mathrm{P}=0.870)$, and duration of physical activity $(\mathrm{P}=0.94)$ between the two groups.

In general, a high to a very high level of reliability was determined, with an Intraclass Correlational Coefficient (ICC) of 0.71 to 0.98 and a Standard Error of Measurement (SEM) of 0.24 to 16.44 . Between group comparison of the neurocognitive function showed significant differences in SRT $(\mathrm{t}=-3.751, \mathrm{P}>0.001)$, CRT $(t=-5.262, P>0.001)$ and number of errors $(t=-3.846$, $\mathrm{P}>0.001)$. Subjects in the control group had a shorter reaction time and fewer errors (Table 1).

\section{Discussion}

A lateral ankle sprain is a common injury in athletes. FAI is a condition that occurs after an ankle sprain and often associated with foot giving way [20-22]. Our results showed that athletes with FAI had significantly slower reaction times and high error rates. Therefore, FAI may adversely affect neurocognitive performance. One potential explanation could be the negative emotional and psychological factors, or preexisting vulnerabilities due to long elapsed time after injury (chronic condition) [28-30].

Williams and Andersen reported that the number of injuries in athletes was significantly related to the narrowing of the visual field under stressful conditions [31]. The finding that the administration of an antidepressant medicine (fluvoxamine) improves the reaction time of healthy subjects provides further evidence of an association between psychosocial stress and reaction time [32].

Table 1. Between-group comparison

\begin{tabular}{cccccc}
\hline \multirow{2}{*}{ Variables } & \multicolumn{3}{c}{ Mean \pm SD } & t & P \\
\cline { 2 - 5 } & Control & FAI & & 0.001 \\
\hline SRT & $295.88 \pm 12.73$ & $333.02 \pm 40.03$ & -3.751 & 0.000 \\
CRT & $419.56 \pm 41.34$ & $506.20 \pm 56.31$ & -5.262 & 0.001 \\
Error & $0.13 \pm 0.33$ & $1.24 \pm 1.18$ & -3.846 & \\
\hline
\end{tabular}

significant differences in simple reaction time (ms); choice reaction time (ms); and the number of errors (t); 18 males were studied In each group; Subjects in the control group had a shorter reaction time and fewer errors

SRT: Simple Reaction Time; CRT: Choice Reaction Time; FAI: Functional Ankle Instability 
As mentioned, after a long time, the psychological and emotional consequences of the chronic injury can lead to depression and anxiety, and these factors are associated with cognitive dysfunction in experimental settings $[33,34]$.

Physical activity requires situational awareness of a broad attentional field to monitor the surrounding environment, to filter irrelevant information continuously, and to execute complex motor programs simultaneously [35-37]. Increased arousal or anxiety influences athletes' concentration, narrows their attentional field, and alters muscle activity, which is associated with poor coordination and inferior performance $[38,39]$.

Dynamic stability of the lower extremity requires a rapid generation of internal torque to counteract external torque that is continuously changing and might be unpredictable. A relatively small delay in neural processing of visual input, or a relatively small narrowing of the peripheral visual field, can have a significant impact on the ability to anticipate external loads. These, in turn, leads to inadequate muscle tension that will result in dynamic joint instability [14, 31].

A typical example used to demonstrate how decreased reaction time contributes to poor performance involves the slowed reactions of distracted drivers during automobile accidents $[40,41]$. In an athletic population, our results agree with previous research suggested that delayed reaction time might be linked with general musculoskeletal injuries [16-19]. Deficits in processing speed and accuracy could make individuals more susceptible to brief errors in judgment or loss of coordination when confronted with complex environmental cues during athletic competition.

To the best of our knowledge, no evidence was found to support the effectiveness of any specific training method for the improvement of information processing speed in competitive athletes. Athletes who exhibit neurocognitive impairment may gain the most significant benefit from activities designed to enhance the responsiveness to visual stimuli. Future research is required to assess the neurocognitive function which can reduce the risk of injury among athletes.

Athletes with FAI had significantly slower reaction times. Therefore, FAI may influence processing speed and accuracy. Future research is needed to shed some light on the probable effects of exercises on neurocognitive processing.

\section{Ethical Considerations}

\section{Compliance with ethical guidelines}

The protocol of study was approved by the Ethics Committee of Tehran University of Medical Sciences (Code: IR.TUMS.FNM.REC.1396.3235) and all participants signed informed consent form.

\section{Funding}

This study was financially supported by Tehran University of Medical Sciences (TUMS).

\section{Authors contributions}

Conceptualization, resources, writing-review-editing methodology: All authors; Investigation: Niloofar Mohammadi; Writing-original draft: Niloofar Mohammadi; Funding acquisitions: Mohammad-Reza Hadian; Supervision: Hadian Oliyaei.

\section{Conflict of interest}

The authors declared no conflict of interest.

\section{Acknowledgements}

We appreciate all stuff of School of Rehabilitation who kindly help us during the term of research.

\section{References}

[1] Lovell M. The management of sports-related concussion current status and future trends. Clinics in Sports Medicine. 2009; 28(1):95-111. [DOI:10.1016/j.csm.2008.08.008] [PMID]

[2] McCrory P, Makdissi M, Davis G, Collie A. Value of neuropsychological testing after head injuries in football. British Journal of Sports Medicine. 2005; 39(Suppl. 1):i58-63. [DOI:10.1136/bjsm.2005.020776] [PMID] [PMCID]

[3] Eckner JT, Kutcher JS, Richardson JK. Pilot evaluation of a novel clinical test of reaction time in National Collegiate Athletic Association Division I football players. Journal of Athletic Training. 2010; 45(4):327-32. [DOI:10.4085/1062-605045.4.327] [PMID] [PMCID]

[4] Collins MW, Grindel SH, Lovell MR, Dede DE, Moser DJ, Phalin BR, et al. Relationship between concussion and neuropsychological performance in college football players. Journal of the American Medical Association. 1999; 282(10):96470. [DOI:10.1001/jama.282.10.964] [PMID]

[5] Covassin T, Elbin III RJ, Stiller-Ostrowski JL, Kontos AP. Immediate Post-concussion Assessment and Cognitive Testing (ImPACT) practices of sports medicine professionals. Journal 
of Athletic Training. 2009; 44(6):639-44. [DOI:10.4085/10626050-44.6.639] [PMID] [PMCID]

[6] Echemendia RJ, Herring S, Bailes J. Who should conduct and interpret the neuropsychological assessment in sports-related concussion? British Journal of Sports Medicine. 2009; 43(Suppl. 1):i32-5. [DOI:10.1136/bjsm.2009.058164] [PMID]

[7] Echemendia RJ, Putukian M, Mackin RS, Julian L, Shoss N. Neuropsychological test performance before and following sports-related mild traumatic brain injury. Clinical Journal of Sport Medicine. 2001; 11(1):23-31. [DOI:10.1097/00042752200101000-00005] [PMID]

[8] Guskiewicz KM, Ross SE, Marshall SW. Postural stability and neuropsychological deficits after concussion in collegiate athletes. Journal of Athletic Training. 2001; 36(3):26373. [PMID] [PMCID]

[9] Hinton-Bayre AD, Geffen GM, Geffen LB, McFarland KA, Frijs P. Concussion in contact sports: Reliable change indices of impairment and recovery. Journal of Clinical and Experimental Neuropsychology. 1999; 21(1):70-86. [DOI:10.1076/ jcen.21.1.70.945] [PMID]

[10] Hutchison M, Comper P, Mainwaring L, Richards D. The influence of musculoskeletal injury on cognition: Implications for concussion research. The American Journal of Sports Medicine. 2011; 39(11):2331-7. [DOI:10.1177/0363546511413375] [PMID]

[11] Macciocchi SN, Barth JT, Alves W, Rimel RW, Jane JA. Neuropsychological functioning and recovery after mild head injury in collegiate athletes. Neurosurgery. 1996; 39(3):510-4. [DOI:10.1227/00006123-199609000-00014] [PMID]

[12] McCrea M, Guskiewicz KM, Marshall SW, Barr W, Randolph C, Cantu RC, et al. Acute effects and recovery time following concussion in collegiate football players: The NCAA Concussion Study. Journal of the American Medical Association. 2003; 290(19):2556-63. [DOI:10.1001/ jama.290.19.2556] [PMID]

[13] Schatz P, Zillmer EA. Computer-based assessment of sports-related concussion. Applied Neuropsychology. 2003; 10(1):42-7. [DOI:10.1207/S15324826AN1001_6] [PMID]

[14] Swanik CB, Covassin T, Stearne DJ, Schatz P. The relationship between neurocognitive function and noncontact anterior cruciate ligament injuries. The American Journal of Sports Medicine. 2007; 35(6):943-8. [DOI:10.1177/0363546507299532] [PMID]

[15] Wilkerson GB. Neurocognitive reaction time predicts lower extremity sprains and strains. International Journal of Athletic Therapy and Training. 2012; 17(6):4-9. [DOI:10.1123/ijatt.17.6.4]

[16] Dault MC, Frank JS, Allard F. Influence of a visuo-spatial, verbal and central executive working memory task on postural control. Gait Posture. 2001; 14(2):110-6. [DOI:10.1016/ S0966-6362(01)00113-8]

[17] Hamstra-Wright KL, Swanik CB, Sitler MR, Swanik KA, Ferber R, Ridenour M, et al. Gender comparisons of dynamic restraint and motor skill in children. Clinical Journal of Sport Medicine. 2006; 16(1):56-62. [DOI:10.1097/01. jsm.0000179232.10261.65] [PMID]

[18] Kirkendall DT, Garrett WE. The anterior cruciate ligament enigma: Injury mechanisms and prevention. Clini- cal Orthopaedics and Related Research ${ }^{\circledR}$. 2000; (372):64-8. [DOI:10.1097/00003086-200003000-00008] [PMID]

[19] Woo E, Burns Y, Johnston L. The effect of task uncertainty onmuscleactivation patternsin8-10 $\square$ year $\square$ old children. Physiotherapy Research International: The Journal for Researchers and Clinicians in Physical Therapy. 2003; 8(3):143-54. [DOI:10.1002/pri.282] [PMID]

[20] Buchanan AS, Docherty CL, Schrader J. Functional performance testing in participants with functional ankle instability and in a healthy control group. Journal of Athletic Training. 2008; 43(4):342-6. [DOI:10.4085/1062-6050-43.4.342] [PMID] [PMCID]

[21] Akbari M, Karimi H, Farahini H, Faghihzadeh S. Balance problems after unilateral lateral ankle sprains. Journal of Rehabilitation Research and Development. 2006; 43(7):819-24. [DOI:10.1682/JRRD.2006.01.0001] [PMID]

[22] Caffrey E, Docherty CL, Schrader J, Klossner J. The ability of 4 single-limb hopping tests to detect functional performance deficits in individuals with functional ankle instability. Journal of Orthopaedic \& Sports Physical Therapy. 2009; 39(11):799-806. [DOI:10.2519/jospt.2009.3042] [PMID]

[23] Maroon JC, Lovell MR, Norwig J, Podell K, Powell JW, Hartl R. Cerebral concussion in athletes: Evaluation and neuropsychological testing. Neurosurgery. 2000; 47(3):659-72. [DOI:10.1097/00006123-200009000-00027] [PMID]

[24] Rahnama L, Salavati M, Akhbari B, Mazaheri M. Attentional demands and postural control in athletes with and without functional ankle instability. Journal of Orthopaedic \& Sports Physical Therapy. 2010; 40(3):180-7. [DOI:10.2519/ jospt.2010.3188] [PMID]

[25] Akhbari B, Takamjani IE, Salavati M, Sanjari MA. A 4-week biodex stability exercise program improved ankle musculature onset, peak latency and balance measures in functionally unstable ankles. Physical Therapy in Sport. 2007; 8(3):117-29. [DOI:10.1016/j.ptsp.2007.03.004]

[26] Kim KJ, Heo M. Effects of virtual reality programs on balance in functional ankle instability. Journal of Physical Therapy Science. 2015; 27(10):3097-101. [DOI:10.1589/jpts.27.3097] [PMID] [PMCID]

[27] Nam SM, Kim WB, Yun CK. Effects of balance training by knee joint motions on muscle activity in adult men with functional ankle instability. Journal of Physical Therapy Science. 2016; 28(5):1629-32. [DOI:10.1589/jpts.28.] [PMID] [PMCID]

[28] Mainwaring LM, Bisschop SM, Green RE, Antoniazzi M, Comper P, Kristman V, et al. Emotional reaction of varsity athletes to sport-related concussion. Journal of Sport and Exercise Psychology. 2004; 26(1):119-35. [DOI:10.1123/ jsep.26.1.119]

[29] Mainwaring LM, Hutchison M, Bisschop SM, Comper $\mathrm{P}$, Richards DW. Emotional response to sport concussion compared to ACL injury. Brain Injury. 2010; 24(4):589-97. [DOI:10.3109/02699051003610508] [PMID]

[30] Hutchison M, Mainwaring LM, Comper P, Richards DW, Bisschop SM. Differential emotional responses of varsity athletes to concussion and musculoskeletal injuries. Clinical Journal of Sport Medicine. 2009; 19(1):13-9. [DOI:10.1097/ JSM.0b013e318190ba06] [PMID] 
[31] Andersen MB, Williams JM. Athletic injury, psychosocial factors and perceptual changes during stress. Journal of Sports Sciences. 1999; 17(9):735-41. [DOI:10.1080/026404199365597] [PMID]

[32] Hasbroucq T, Rihet P, Blin O, Possamaï CA. Serotonin and human information processing: Fluvoxamine can improve reaction time performance. Neuroscience Letters. 1997; 229(3):204-8. [DOI:10.1016/S0304-3940(97)00451-5]

[33] Holmes AJ, Pizzagalli DA. Task feedback effects on conflict monitoring and executive control: Relationship to subclinical measures of depression. Emotion. 2007; 7(1):68-76. [DOI:10.1037/1528-3542.7.1.68] [PMID] [PMCID]

[34] Mathews A. Why worry? The cognitive function of anxiety. Behaviour Research and Therapy. 1990; 28(6):455-68. [DOI:10.1016/0005-7967(90)90132-3]

[35] Landers DM, Qi WM, Courtet P. Peripheral narrowing among experienced and inexperienced rifle shooters under low-and high-stress conditions. Research Quarterly for Exercise and Sport. 1985; 56(2):122-30. [DOI:10.1080/02701367.19 85.10608446]

[36] Nideffer RM. Comparison of self-report and performance measures of attention: A second look. Percept Mot Skills. 1977; 45(Suppl. 3):1291-4. [DOI:10.2466/pms.1977.45.3f.1291] [PMID]

[37] Weinberg RS, Hunt VV. Effects of structural integration on state $\square$ trait anxiety. Journal of Clinical Psychology. 1979; 35(2):319-22. [DOI:10.1002/1097-4679(197904)35:23.0.CO;2-3]

[38] Consiglio W, Driscoll P, Witte M, Berg WP. Effect of cellular telephone conversations and other potential interference on reaction time in a braking response. Accident: Analysis and Prevention. 2003; 35(4):495-500. [DOI:10.1016/S00014575(02)00027-1]

[39] Ebersbach G, Dimitrijevic MR, Poewe W. Influence of concurrent tasks on gait: A dual-task approach. Perceptual and Motor Skills. 1995; 81(1):107-13. [DOI:10.2466/ pms.1995.81.1.107] [PMID]

[40] Taimela S. Relation between speed of reaction and psychometric tests of mental ability in musculoskeletal injury-prone subjects. Perceptual and Motor Skills. 1990; 70(1):155-61. [DOI:10.2466/pms.1990.70.1.155] [PMID]

[41] Taimela S, Kujala UM. Reaction times with reference to musculoskeletal complaints in adolescence. Perceptual and Motor Skills. 1992; 75(Suppl. 3):1075-82. [DOI:10.2466/ pms.1992.75.3f.1075] [PMID] 